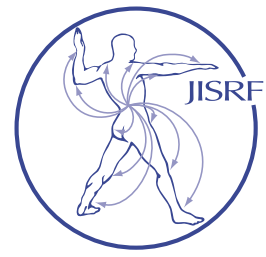

\title{
Coronal Alignment in TKA: Traditional Principles Versus New Concepts
}

Parisi $T^{1}$, Jennings $\mathrm{J}^{1,3}$, Dennis $D^{1,2,3,4}$

\section{Abstract}

Background: Up to $20 \%$ of total knee arthroplasty (TKA) patients are not satisfied with their outcome, and coronal alignment is considered an important variable in attaining a well-functioning TKA. Neutral mechanical alignment is not necessarily the anatomic norm and has led some surgeons to advocate a shift in defining and attaining the optimal coronal component alignment. Our aim was to review the different coronal alignment paradigms of TKA and summarize the historical and contemporary outcomes of different alignment techniques.

Methods: A systematic review was performed in March 2017 via PubMed using the search terms: coronal alignment, kinematic alignment, and total knee replacement using Boolean "and" in-between terms. Relevant results were then reviewed, analyzed and summarized

Conclusions: Early clinical outcomes of kinematically aligned TKAs are promising, but long-term clinical results are unknown. Clinical, laboratory, and retrieval studies suggest that mechanical varus in TKA, especially involving the tibial component, may result in earlier failure. Kinematic alignment with boundaries may be an optimal strategy for patients with pre-operative constitutional varus or congenital tibia vara.

Keywords: total knee arthroplasty; kinematic alignment; coronal alignment; mechanical alignment Level of Evidence: AAOS Therapeutic Level III

\section{Background}

\section{The importance of coronal alignment in total knee arthroplasty}

Coronal alignment is considered an important variable in attaining a well-functioning TKA. [1-4] Proper alignment improves soft tissue balance and decreases mechanical and shear stresses placed on the implant fixation interface as well as on articular bearing surfaces. [46] Malalignment results in decreased functional outcomes and survivorship, and has been implicated as a cause of early failure due to wear and loosening, [2, 4-10] particularly in older implants of non-highly crosslinked polyethylene. [11] Most surgeons follow the tenet that post-operative alignment should be within $3^{\circ}$ of a neutral mechanical axis. [ $\underline{4}-\underline{6}, \underline{9}, \underline{12}-\underline{16}]$ However, up to $20 \%$ of TKA patients are dissatisfied, $[\underline{17}, \underline{18}]$ with some evidence that coronal alignment plays a role in patient satisfaction. $[\underline{19}, \underline{20}]$ As such, substantial research and resources have been invested in defining optimal mechanical alignment, [21-24] as evidenced by recent developments in computer navigation, patient-specific instrumentation, and support for kinematically-aligned TKA. [므-27]

\section{Anatomy and Alignment: Traditional Theories}

Definition of the anatomical framework is required to understand different theories of coronal alignment (Table 1, Figure 1). Native knee alignment varies throughout the 
Table 1: Axes and Angles of Lower Extremity Alignment

\begin{tabular}{|c|c|}
\hline AXES & DEFINITION \\
\hline Vertical Axis & $\begin{array}{l}\text { Is referenced from a vertical midline extending } \\
\text { distally from the center of the pubic symphysis. } \\
\text { It determines overall alignment of the lower } \\
\text { extremity. [26] }\end{array}$ \\
\hline Anatomic Axes & 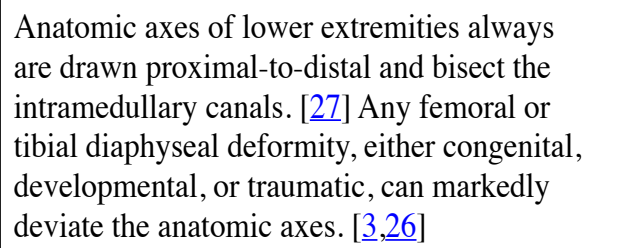 \\
\hline $\begin{array}{l}\text { - Anatomic } \\
\text { Femoral Axis }\end{array}$ & $\begin{array}{l}\text { Is typically approximately } 9^{\circ} \text { of valgus } \\
\text { compared to midline, and } 5^{\circ} \text { to } 7^{\circ} \text { valgus to the } \\
\text { mechanical axis. }[\underline{3}, \underline{14}, \underline{6}]\end{array}$ \\
\hline $\begin{array}{l}\text { - Anatomic } \\
\text { Tibial Axis }\end{array}$ & $\begin{array}{l}\text { Is typically in approximately } 3^{\circ} \text { of varus } \\
\text { compared to the vertical axis and approximates } \\
\text { the mechanical axis. }[\underline{3}, \underline{14}, \underline{26}]\end{array}$ \\
\hline $\begin{array}{l}\text { Mechanical } \\
\text { Axis }\end{array}$ & $\begin{array}{l}\text { Is defined by a line drawn from the center of } \\
\text { the femoral head to the center of the talus, and } \\
\text { typically is approximately } 3^{\circ} \text { valgus to the } \\
\text { vertical axis. }[\underline{3}, \underline{27}, \underline{26}]\end{array}$ \\
\hline $\begin{array}{l}\text { - Mechanical } \\
\text { Femoral Axis }\end{array}$ & $\begin{array}{l}\text { Runs from the center of the femoral head to the } \\
\text { intercondylar notch. }[\underline{3}, \underline{14}, \underline{26}]\end{array}$ \\
\hline $\begin{array}{l}\text { - Mechanical } \\
\text { Tibial Axis }\end{array}$ & $\begin{array}{l}\text { Runs from the center of the proximal tibia to the } \\
\text { center of the talus. }[\underline{3}, \underline{14}, \underline{26}]\end{array}$ \\
\hline AXES & DEFINITION \\
\hline $\begin{array}{l}\text { Hip-Knee- } \\
\text { Ankle Angle } \\
\text { (HKA) }\end{array}$ & $\begin{array}{l}\text { Is created via intersection of the mechanical axis } \\
\text { of the femur and tibia. It is typically just under } \\
180^{\circ} \text {, and passes just medial to the tibial spine. } \\
{[\underline{3}, \underline{28}]}\end{array}$ \\
\hline $\begin{array}{l}\text { Anatomic } \\
\text { Femorotibial } \\
\text { Angle (AFT) }\end{array}$ & $\begin{array}{l}\text { Is formed by intersection of the anatomic } \\
\text { femoral axis and the joint line and is typically } \\
\text { approximately } 6^{\circ} \text { of valgus. }\end{array}$ \\
\hline $\begin{array}{l}\text { Mechanical } \\
\text { Femorotibial } \\
\text { Angle (MFT) }\end{array}$ & $\begin{array}{l}\text { Is formed between the mechanical femoral }\left(3^{\circ}\right. \\
\text { valgus) and tibial axes }\left(3^{\circ} \text { varus }\right) \text {, resulting in } \\
0^{\circ} \text {, or so-call neutral mechanical alignment. } \\
{[\underline{3}, \underline{14}, \underline{26}] \text { The MFT is essentially the same as the }} \\
\text { HKA. [29] }\end{array}$ \\
\hline $\begin{array}{l}\text { Femorotibial } \\
\text { Angle (FTA) }\end{array}$ & $\begin{array}{l}\text { Is the lateral angle created between the anatomic } \\
\text { axes of the femur and tibia. On average, it is } \\
178^{\circ} \text { in men and } 174^{\circ} \text { in women. }[\underline{3}, \underline{27}]\end{array}$ \\
\hline
\end{tabular}

population, and neutral mechanical alignment, defined as $0^{\circ}$, is not always observed in healthy, non-arthritic patients. [12] Hsu et al. [료] found the hip-knee-ankle angle (HKA) of normal adults was actually $1.2^{\circ}$ of varus and only $2.2 \%$ had a HKA of $0^{\circ}$. Fahlman et al. [르] found only $11 \%$ of 143 patients had bilateral mechanically-neutral knees, with $49 \%$ aligned in mechanical varus, and $22 \%$ aligned in mechanical valgus. In asymptomatic adults, constitutionally varus knees (HKA $>3^{\circ}$ varus) has been found in up to $32 \%$ of men and $17 \%$ of women. [1] Conversely, in a popula-

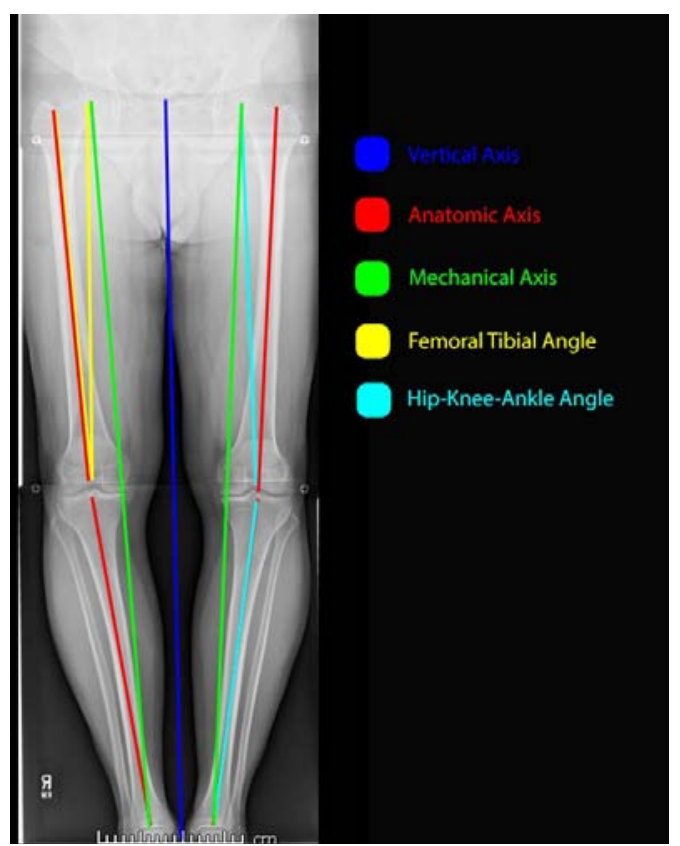

Figure 1: Illustration, demonstrating the different axes of the knee. The dark-blue line represents the vertical axis extending distally from the center of the pubic symphysis. The red lines represent the anatomic axes overall, as well as of the femur and tibia. Anatomic axes of lower extremities always are drawn proximal-to-distal and bisect the intramedullary canals. The anatomic femoral axis is typically approximately $9^{\circ}$ of valgus compared to midline, and $5^{\circ}$ to $7^{\circ}$ valgus to the mechanical axis. The anatomic tibial axis is typically in approximately $3^{\circ}$ of varus compared to the vertical axis and approximates the mechanical axis. The green line represents the mechanical axis, defined by a line drawn from the center of the femoral head to the center of the talus, and typically is approximately $3^{\circ}$ valgus to the vertical axis. The yellow lines represent the femoral tibial angle which is formed by the intersection of the anatomic femoral axis and the joint line and is typically approximately $6^{\circ}$ of valgus. The light-blue line represents the hip-knee-ankle angle which is created via intersection of the mechanical axis of the femur and tibia, and is typically just under $180^{\circ}$, and passes just medial to the tibial spine.

tion of symptomatic osteoarthritic patients, $71 \%$ had varus alignment with a mean HKA of $-9.0^{\circ}$. [30] Additionally, Vandekerckhove et al. [52], have shown that constitutional varus does contribute to a higher incidence of osteoarthritis in the general population.

\section{Anatomic Alignment}

The premise of anatomic alignment is that optimal component position should recreate the anatomic joint line based on long-standing roentgenograms to attain an axis extending from the center of the knee to the femoral head and ankle joint. [31] This alignment technique attempts to place the joint line parallel to the ground during the bilateral limb stance phase of normal gait. [31] However, given 
that surgeons accurately place components within $3^{\circ}$ of the desired target less than $70 \%$ of the time with conventional TKA instrumentation, aiming for $2-3^{\circ}$ of varus may result in outliers which could predispose to early failures. [32]

\section{Mechanical Alignment}

Mechanical alignment is performed by cutting both the femur and tibia perpendicular to their respective mechanical axes. [33] This results in a TKA femoral-tibial angle of approximately $5^{\circ}-7^{\circ}$ of valgus with the purpose of creating even load distribution across the joint. [프] Advocates of mechanical alignment feared that anatomic alignment would increase medial loads and risk medial tibial component fixation failure. [35]

Restoration of mechanical alignment to $0^{\circ}$ may increase component longevity and has demonstrated a 3\% loosening rate when the mechanical axis crossed the middle $1 / 3 \mathrm{rd}$ of the prosthesis versus $24 \%$ when the mechanical axis was shifted medially or laterally.5 Similarly, Fang et al. [12] found neutral mechanical alignment had a lower failure rate $(0.5 \%)$ than varus $(1.8 \%)$ or valgus $(1.5 \%)$. Other authors have reported similar findings.20,36 This is supported in wear analysis of TKA retrievals. $[\underline{5}, \underline{7}, \underline{11}, \underline{19}, \underline{22}, \underline{30}, \underline{37}, \underline{38}]$ Lastly, BMI may play a role in failure of the tibial component. Berend et al. [9] found a 168 times higher failure rate if the tibia component was positioned in varus $\left(\geq 3^{\circ}\right)$ in conjunction with a BMI $>33.7 \mathrm{~kg} / \mathrm{m} 2$.

Conversely, other studies have not demonstrated significant survivorship differences for TKAs placed outside of the $0 \pm 3^{\circ}$ traditional "safe zone". [22, $\left.24, \underline{34}-\underline{36}\right]$ Parratte et al. $[\underline{22}, \underline{30}]$ found no differences in 15 and now 20 -year survival of mechanically aligned knees $\left(0^{\circ} \pm 3^{\circ}\right)$ versus those marginally outside of these parameters $\left(4^{\circ}-6^{\circ}\right)$. Bonner et al. [느] stratified TKA patients into "aligned" $\left(0^{\circ} \pm 3^{\circ}\right)$ and "malaligned" (deviation $>3^{\circ}$ ) groups and found slightly higher 15-year survival in the aligned group, although the difference was not statistically significant. [34] Similarly, Morgan et al. [35] found no difference in survivorship of TKAs independent of neutral, valgus or varus AFT. Matziolis et al., [24] found no outcome differences in TKAs aligned in mechanical varus versus those in neutral. A review of TKAs performed on patients with pre-operative varus gonarthrosis showed no functional difference between TKAs aligned in post-operative mechanical varus versus neutral, as well as no difference in revision rates. [37] Similarly, Hadi et al. [38] did not find increased revision rates of malaligned TKAs measured using the mechanical axis, but did find an association between malalignment and revision rate using an anatomical axis. Lastly, some evidence suggests patients placed in mechanical varus have an increase in satisfaction after TKA. Vanlommel et al. [36] evaluated TKAs in pre-operative varus and found those left in mild mechanical varus $\left(3^{\circ}\right.$ to $\left.6^{\circ}\right)$ had superior post-operative Knee Society (KSS) and Western Ontario and McMaster Universities Arthritis Index (WOMAC) scores compared to knees corrected to neutral or those left in increased varus $\left(>6^{\circ}\right)$.

Even if mechanically aligned on static radiographs, there is evidence that dynamic loading of a mechanically neutral TKA may not be balanced. [39-41] Miller et al. [39] found static neutral mechanical alignment $\left(0^{\circ} \pm 3^{\circ}\right)$ in 13 of 15 knees, but only 7 of 15 had balanced dynamic loading with gait testing. In cadaveric knee analysis, Delport et al. [42] showed decreased physiological strain in collateral ligaments when TKAs were restored to $\pm 2^{\circ}$ of constitutional alignment versus neutral mechanical alignment.

\section{Kinematic TKA Alignment}

\section{History and Definition of Kinematic Alignment}

Kinematic alignment TKA technique evolved from kinematic studies. $[\underline{43}, \underline{44}]$ Its basic principle is attempted restoration of a patient's pre-arthritic anatomy and axes of the knee, while creating a balanced TKA throughout the entire arc of motion. Specifically, it attempts to three-dimensionally align the distal and posterior femoral joint lines of the femoral component to the original primary transverse axis of the femur and joint line of the tibia to a patient's pre-arthritic state. [18] This could be achieved by transforming the arthritic knee to its pre-arthritic state via 3D modeling from a preoperative CT scan or MRI, [45] or by, more simply, performing tibial resection in $2^{\circ}-3^{\circ}$ of varus. [21] It proposes three axes which govern the movement of the patella and tibia with respect to the femur: a primary transverse axis within the femur about which the tibia flexes and extends, a second transverse axis in the femur, parallel and proximal to the first and about which the patella flexes and extends, and a third axis in the tibia which is longitudinal and perpendicular to the others (Figure 2). [45]

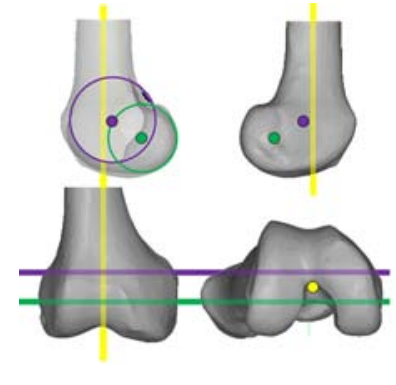

Figure 2: Illustration, demonstrating the three kinematic axes of the knee. Yellow line indicates the longitudinal axis in the tibia about which the tibia rotates on the femur. The green line indicates the transverse axis in the femur about which the tibia flexes and extends. The magenta line indicates the transverse axis in the femur about which the patella flexes and extends. 
The goal of kinematic alignment is to co-align the transverse axes and restore any difference in symmetry and coronal laxity between full extension and $90^{\circ}$ of flexion of the normal knee. [45,46] As such, the thickness of all femoral bone resections including worn cartilage and bone from the saw kerf is equal to the thickness of the femoral component. [45] Restoration of the pre-arthritic joint line level and obliquity to minimize soft tissue releases, may provide the patient with a more "naturally feeling" knee and improve patient satisfaction as theorized by proponents of kinematic alignment.

To perform kinematic alignment, use of patient-specific instrumentation, computer navigation, or measurement calipers is required to achieve the desired level of precision needed for bone cuts. [47] If even small errors in resection occur, resulting in excessive tibial varus $\left(>5^{\circ}\right)$, one risks premature tibial component failure. [47] Additionally, most kinematic alignment surgeons utilize PCL-retaining TKAs. [47]

\section{Proposed Advantages and Disadvantages of Kinematically Aligned TKA}

\section{Theoretical Advantages}

Bellemans et al. $[\underline{48}, \underline{49}]$ have suggested that restoring patients with constitutional varus to neutral mechanical alignment may not optimize outcomes. Using kinematic alignment principles to instead resect the tibia in a few degrees of varus and re-establish the obliquity and location of the pre-arthritic joint line, in theory, should require less soft tissue releasing and result in a more "natural feeling" TKA. [47] Vanlommel et al. [36] showed that pre-operatively varus-deformed knees that were left in mild mechanical varus $\left(3^{\circ}\right.$ to $\left.6^{\circ}\right)$ at TKA had superior post-operative functional scores compared to knees corrected to mechanical neutral $\left(0^{\circ} \pm 3^{\circ}\right)$.

\section{Theoretical Disadvantages}

Due to the risk of over-correction and cutting the tibia in excessive varus, surgeons performing kinematic alignment should consider using computer navigation or patient specific instrumentation to maximize precision. [47] A recent meta-analysis showed that mechanical axis malalignment greater than $\pm 3^{\circ}$ occurred $31.8 \%$ of the time using conventional TKA alignment techniques, versus $9.0 \%$ using computer navigation. [르]

Additionally, there is a three-decade history of satisfactory results with mechanically aligned TKAs in subjects with a wide range of limb alignment and arthritic deformities. Increased polyethylene stresses associated with malalignment has been shown by numerous reports to result in premature TKA failure. $[\underline{5}, \underline{7}, \underline{9}, \underline{11}, \underline{15}, \underline{50}, \underline{51}]$ Three laboratory studies have shown that $3^{\circ}-5^{\circ}$ of mechanical varus leads to uneven load distribution with increased compressive loading and medial wear. $[\underline{6}, \underline{53}, \underline{54}]$ Additionally, three retrieval analyses suggested that overall varus TKA alignment is correlated with increased wear and damage. [55- 57] Two of three suggested if the tibial component was placed in varus but overall mechanical alignment was in neutral, then there was no increase in wear or damage. [55, $\underline{66}$ ] D'Lima et al. [ㄷ] reported increased wear anytime the tibia was in varus, even if overall alignment was neutral. Additionally, cadaveric studies have consistently found that varus alignment causes increased posteromedial strain and medial loading pressures with decreased loads to implant failure. $[\underline{13}, \underline{16}, \underline{58}]$ Ritter et al., demonstrated increased failure rates with mechanical varus $>2.5^{\circ}$, and as previously mentioned, Berend et al., demonstrated a 168 time increase in failure with a tibia in mechanical varus and BMI $>33.7$. $[9,14]$ As such, the predominance of studies suggest that mechanical varus in TKA, especially involving the tibial component, may result in earlier TKA failure.

\section{Techniques of Kinematically Aligned TKAs}

\section{Traditional Kinematic Alignment Techniques}

Kinematically alignment technique using patient-specific femoral and tibial cutting guides was developed and described in 2005. [45] It required special software to create and transform a patient's arthritic knee to its non-arthritic state via a 3D model generated by magnetic resonance or computed tomography imaging. This was then used to create patient-specific cutting guides based on kinematic alignment principles. To eliminate the expense of patient-specific instrumentation and allow for broader use of kinematic alignment, Howell revised his technique to use modified generic instrumentation, and educated estimations of cartilage and bone wear. $[\underline{26}, \underline{59}]$ Femoral implant placement is based on the primary transverse axes about which the tibia and the patella flex and extend. The distal femoral cutting guide is manually placed just posterior to the notch apex, flush with the 'unworn' side and manually raised away from the 'worn' side to correct for wear. The goal is to perform a resection equal to the distal thickness of the femoral component with symmetric medial and lateral condylar thickness minus the thickness of the estimated cartilage and bone erosion on the worn side). For example, if the component width is $9 \mathrm{~mm}$ and the surgeon estimates $2 \mathrm{~mm}$ of cartilage and $1 \mathrm{~mm}$ of osseous wear, $9 \mathrm{~mm}$ is resected from the unworn side versus $6 \mathrm{~mm}$ from the worn condyle (Figure 3). The posterior referenc- 


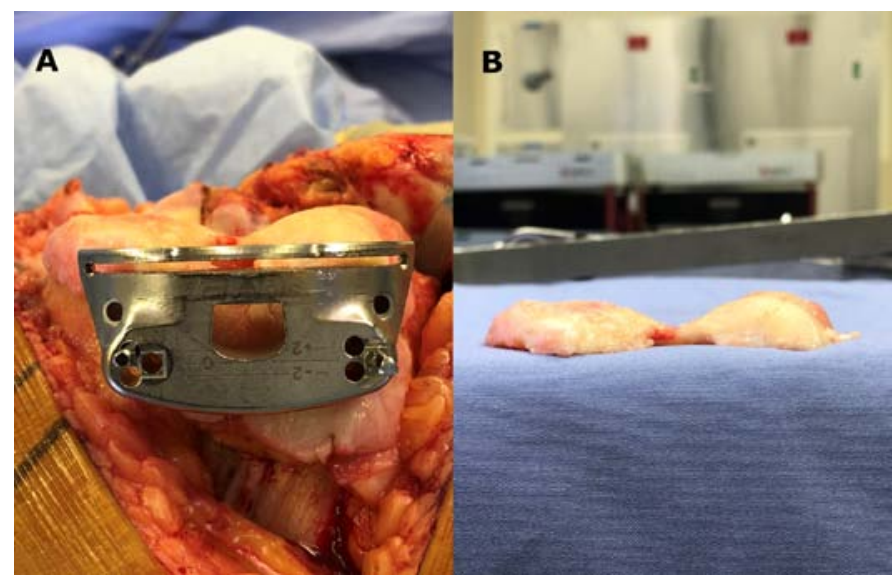

Figure 3A \& 3B: Intraoperative photographs demonstrating placement of the distal femoral cutting guide (A) and subsequent distal femoral condylar resected bone $(B)$ with a goal of resection width equaling the distal femoral component thickness and similar condylar thicknesses considering the thickness of cartilage and bone loss from the worn condyle.

ing guide is set at neutral rotation to assure an equal resection thickness of the posterior aspects of the medial and lateral condyles because typical posterior cartilage wear is minimal (Figure 4). Chamfer cuts are made to match the best-fitting femoral component.

The tibial cutting guide is set according to native varusvalgus alignment and, like the femur, is adjusted so resection of the 'worn' side is thinner than the 'unworn' side by the amount of estimated wear present. Posterior tibia slope is set to neutral (duplicating native posterior tibial slope) to preserve the PCL insertion (Figure 5).

To balance the knee, a stepwise algorithm is proposed (Figure 6). [45] Generally, the first step is to confirm symmetric and equal bony cuts measured via caliper once corrected for cartilage, bone wear, and saw-blade kerf. [45]

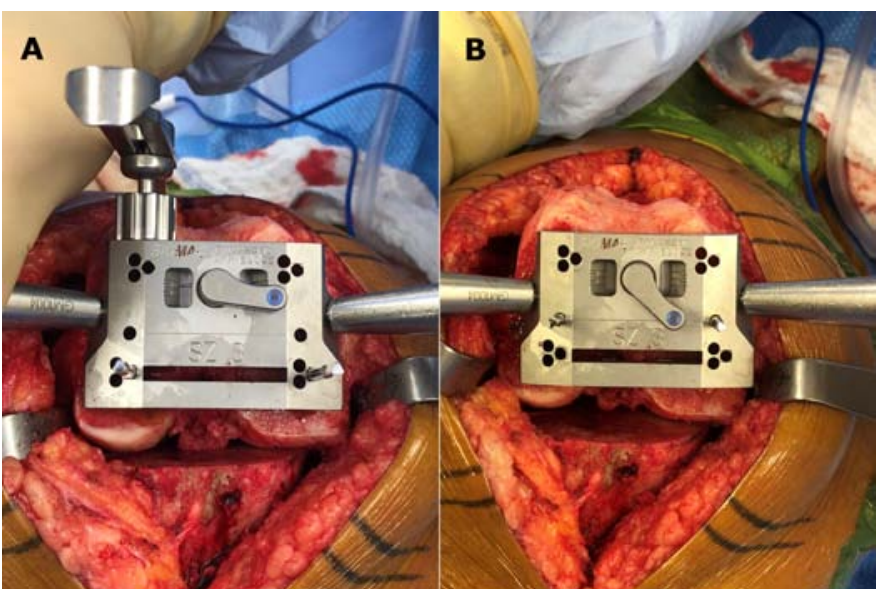

Figure 4A \& 4B: Intraoperative photographs of the AP cutting block positioned for kinematic alignment (A); equal posterior condylar bone resections) versus traditional alignment $(B)$ seeking external rotation of the femoral component relative to the posterior condylar axis.

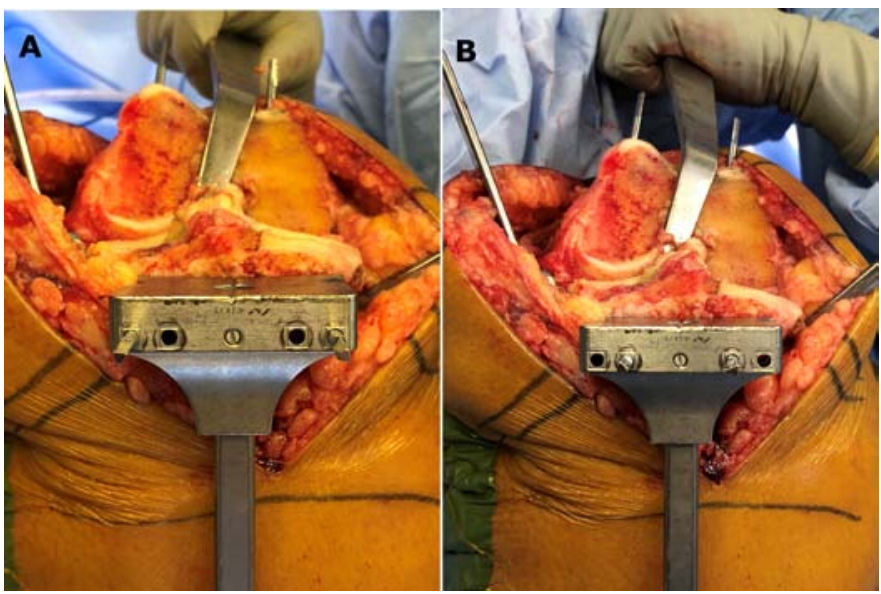

Figure 5A \& B: Intraoperative photographs of the tibial cutting jig positioned for kinematic alignment (A); equal medial and lateral condylar resections considering wear) versus traditional mechanical alignment in which less bone is resected medially $(B)$.

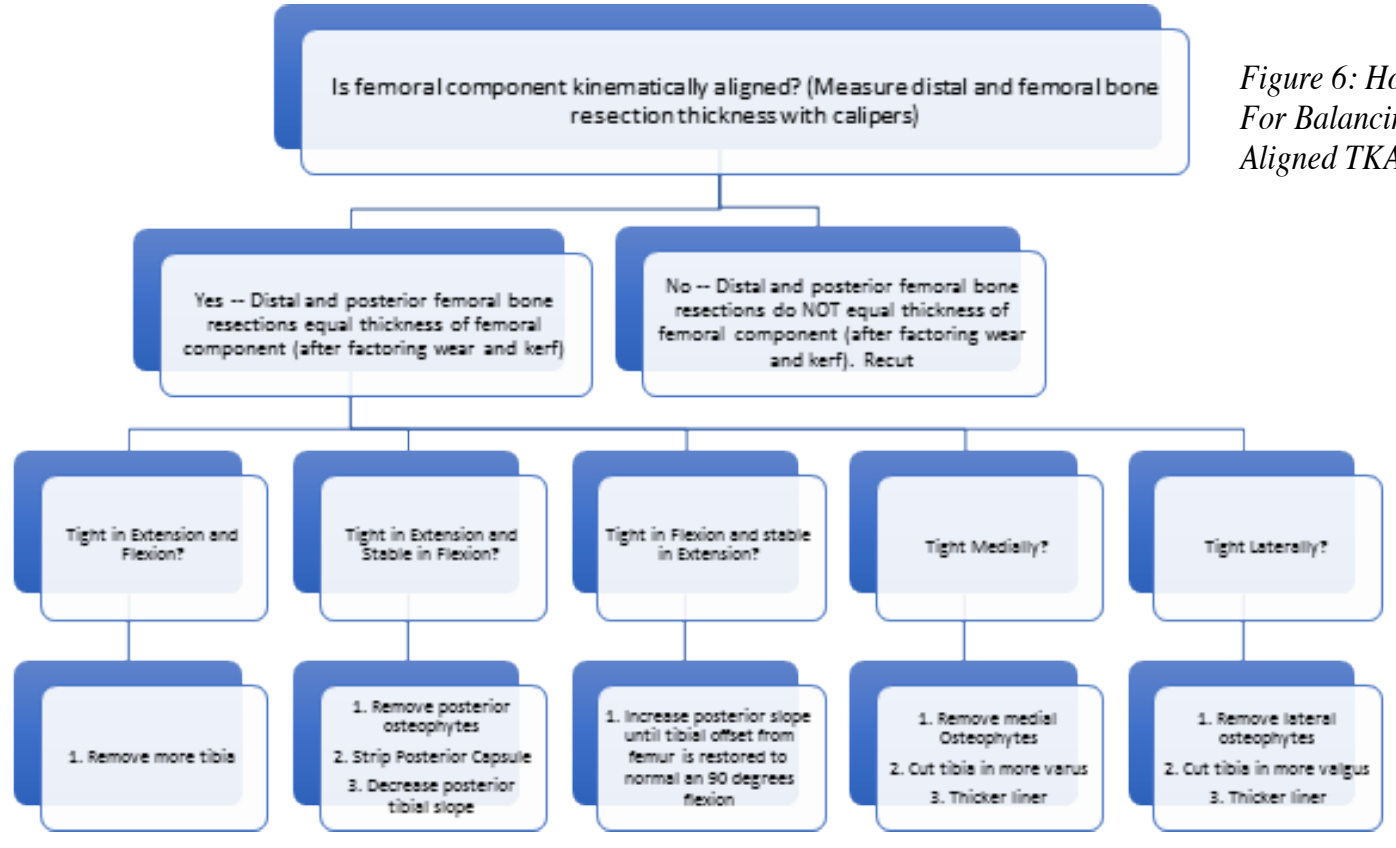


Sagittal balancing technique is similar to mechanical alignment with typical steps to address a TKA tight in flexion and or extension. Coronal balance, however, is quite different. Although both begin with the removal of osteophytes, if a TKA is tight medially in a kinematically aligned knee, the next step would be to cut the tibia in more varus rather than perform soft tissue releasing. [45] Similarly, if the knee is too tight laterally, rather than pie-crust the arcuate ligament and iliotibial band, kinematic alignment suggests re-cutting the tibia in more valgus. [45]

\section{Kinematic Alignment Using Computer Navigation}

Kinematically aligning TKAs using computer navigation has been described as well. [60] Distal femoral and proximal tibial resection amounts are set to equal TKA implant thickness. Cartilage and bone loss is assessed by comparing intact areas. If subchondral bone is exposed, it is considered to represent $3 \mathrm{~mm}$ of cartilage loss and coronal resection angles are adjusted accordingly. $[\underline{60}, \underline{61}]$ If partial thickness cartilage loss is present, it is estimated intraoperatively, and again, resection angles are adjusted. In their technique, Hutt et al. suggest keeping resections within a "safe range" of either combined coronal orientation within $\pm 3^{\circ}$ of neutral or limiting the lateral distal femoral and medial proximal tibial angles to $\pm 5^{\circ}$. [ 60$]$ All cuts are confirmed by caliper measurements intraoperatively. Posterior femoral condylar resections are completed using a posterior referencing technique set to neutral rotation to only resect the thickness of implant posterior condyles and match each patient's native femoral rotation. In their series of 100 TKAs completed using this technique, only $5 \%$ required any ligamentous release and at mean follow-up of 2.4 years, the mean HKA angle was $0.5^{\circ}$ varus (from $4.6^{\circ}$ varus pre-operatively), and WOMAC and KOOS scores improved. [60] They concluded that kinematically aligned TKA using computer navigation is reproducible and offers good short-term results, and pending long-term studies, may be a viable option to partially correct extreme anatomy that may perform unsatisfactorily with traditional mechanical alignment. [무]

\section{Kinematic Alignment with Boundaries}

Many surgeons today would agree that coronal alignment plays an important role in the survival and clinical outcomes of TKA. Continued debate occurs as to what the ideal alignment should be as well as the best method to obtain it. [2ㅡㄴ $\underline{64}$ ] Some experts suggest that ideal alignment is probably patient specific and a fixed amount of varus or valgus resection is not ideal. [62] Some surgeons have begun performing variations of classic kinematic alignment as described by Howell, [50] limiting the technique to patients with substantial varus alignment, such as constitutional varus or congenital tibial vara. In these patients, surgeons limit varus tibial resection to a maximum $3^{\circ}$ to avoid excessive medial tibial loads and restrict distal femoral valgus resection to a range of $2-8^{\circ}\left(5^{\circ} \pm 3^{\circ}\right.$ of valgus $)$ with the goal of removing a similar amount of bone from medial and lateral distal femoral condyles. While classic kinematic alignment proposes equal posterior condylar resection, some surgeons will vary the thickness of medial vs. lateral posterior resections to assure gap balance in flexion. These variations from classic kinematic alignment have been referred to by some as "kinematic alignment with boundaries." They are briefly mentioned here to reflect the thoughts of surgeons interested in challenging the traditional concept of aligning all TKAs to neutral mechanical alignment. The authors cannot recommend or dispute these alignment variations as valuable data with their use are not yet available.

\section{Outcomes of Kinematically Aligned TKAs}

Unfortunately, there are no clinical studies evaluating the long-term clinical outcomes of kinematically aligned TKAs. Howell et al. [25] has published a 31-month followup of 214 kinematically aligned knees divided into three groups based on the mechanical axis: TKAs in $>3^{\circ}$ varus, TKAs in $>3^{\circ}$ valgus, and TKAs in the neutral range of $0^{\circ} \pm 3^{\circ}$. Postoperatively, all had similar WOMAC and Oxford Knee Scores (OKS), and there were no catastrophic failures or need for TKA revision for loosening, instability or wear, even with tibial varus outliers to $9^{\circ}$. Similarly, Dossett et al. [65] performed a randomized control trial (RCT) comparing 88 TKAs, 44 which underwent kinematic alignment and 44 which underwent mechanical alignment. At two-years, those who underwent kinematic alignment had statistically significant improvement in WOMAC, KSS, and OKS scores as well as higher mean flexion and less pain than those with mechanical alignment. In a multicenter patient questionnaire study, patients who had a kinematically aligned TKA were three-times more likely to state their knee felt more 'normal' compared to those with a mechanically aligned TKA. [66]

More recently, studies have not been able to find any clinical difference in kinematically versus mechanically aligned TKAs. Howell et al. [ㄷ] re-evaluated 219 kinematically aligned knees at a mean follow-up of 6.3 years, again showing no difference in functional outcomes, WOMAC, or OKS. Kinematically aligned knees had a 97.5\% survivorship with one deep infection, one loose tibial component, and two loose patellar components. Similarly, Young et al. [68] performed a RCT of 99 TKAs, 
comparing mechanical to kinematically aligned TKAs. At 2 years, no difference was observed in OKS, WOM$\mathrm{AC}$ or Forgotten Joint scores between the two groups, nor was there any difference in complication rates. HKA axis did not differ between groups, but kinematically aligned TKAs had $1.9^{\circ}$ more tibial varus and $1.6^{\circ}$ more femoral valgus than the mechanically aligned group. Interestingly, a recent retrospective review of 361 consecutive primary TKAs found that in knees with preoperative varus alignment, those that were corrected to mechanical neutral actually had improved median KSS when compared to those left in residual varus. [우]

Finally, a meta-analysis including 877 kinematically aligned TKAs with a mean follow-up duration of 37.9 months found a cumulative survivorship of 97.4\%.70 There was a $1.2 \%$ revision rate for patellofemoral problems, but kinematic versus conventionally aligned TKAs demonstrated no differences in complication rates. Additionally, the kinematic group had a higher combined postoperative KSS (mean difference of 9.1 points). Authors concluded that overall survivorship or complication rates do not differ, but that functional outcomes favor kinematically aligned TKAs in the short term.

\section{Kinematic Alignment: Questions Remaining}

\section{Will placement of the tibial component in varus affect} long-term wear and fixation?

There are a number of previous studies that have shown inferior results of TKAs with the tibial component positioned in varus alignment. $[\underline{9}, \underline{37}, \underline{54}, \underline{71}]$ Since we know that constitutional varus contributes to a higher incidence of knee osteoarthritis in the non-implanted knee, will the varus positioning of the tibial component similarly cause accelerated medial wear of the polyethylene bearing after TKA? While current clinical studies of kinematically aligned TKAs have not shown higher rates of tibial loosening, radiographically noticeable polyethylene wear or osteolytic lesions, these studies have limited follow-up duration. Longer term data, as well as fluoroscopic, in-vivo, weight bearing kinematic analyses, are needed to truly assess the longevity and functional outcomes overtime.

Will removal of one or both cruciate ligaments during TKA affect the precision of the transverse axes utilized for implant positioning in kinematically aligned TKA?

Kinematic alignment in TKA strives to restore native flexion-extension and longitudinal rotation axes of the tibiofemoral joint. [44] However, the work performed by Hollister, et al. [49] was performed on native cadaveric knees that still had intact anterior cruciate (ACL) and posterior cruciate ligaments (PCL). The ACL is typically sacrificed during TKA, and a substantial number of surgeons implant posterior cruciate substituting (PS) TKAs. Will sacrificing the PCL change the flexion-extension and longitudinal rotation axes Hollister described?

A study of nine cadaver knees pre- and post- ACL reconstruction found significant changes in the longitudinal axes of rotation after ACL reconstruction with a relatively large $(2.1 \mathrm{~mm})$ medial translation. [72] Smaller changes were also present in the anterior to posterior axis $(0.3 \mathrm{~mm}$ shift posteriorly) as well as the internal-external rotation axis $\left(0.5^{\circ}\right.$ of internal rotation). [72] This intuitively makes sense as posteromedial wear is common in osteoarthritic knees after ACL attenuation. [73] Kinematic analysis of ACL deficient native knees has shown increased mean contact stresses especially posteromedially. [74] What is unclear is whether the varus alignment from kinematically aligned TKAs, accentuated by the lack of the ACL, will increase the medial tibial load enough to predispose kinematically aligned TKAs to earlier failure. Similarly, a PCL deficient knee also experiences increased tibiofemoral contact stresses in the medial compartment. [75] While the main implementers of kinematic alignment implant cruciate retaining $(\mathrm{CR})$ prostheses, a significant proportion of surgeons implant PS TKAs. [47] As such, it also stands to question whether performing kinematic alignment in PS implant designs will lead to increased contact stresses and earlier failure. These data stimulate the question of whether kinematic alignment is a concept best suited to bicruciate-retaining TKA.

Internal rotation of femoral and tibial components has been frequently observed with use of kinematic alignment in TKA. Will these rotational variances have long-term effects on patellar tracking, wear, or fixation in addition to limiting postoperative knee flexion?

In the kinematically aligned TKA, the optimal rotation of the femoral component in the axial plane is based on restoration of the posterior femoral joint line of the pre-arthritic knee. This is in-contrast to conventional techniques of determining rotation by placement perpendicular to the anterior-posterior axis, parallel to the transepicondylar axis (TEA), or parallel to the resected tibia with each collater-

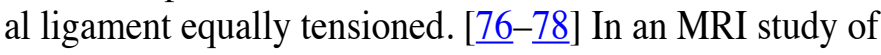
114 kinematically aligned TKAs, the mean posterior femoral axis was found to be $4^{\circ}$ internally rotated when compared to the TEA. [79] A separate analysis of 101 kinematically aligned TKAs found femoral rotation to range from $-3^{\circ}$ internal to $2^{\circ}$ external, and tibial rotation to vary from $-11^{\circ}$ internal to $12^{\circ}$ external. [우 ] This same analysis found a weak negative association between internal malrotation 
and $\mathrm{OKS}$ and WOMAC scores. [우] Internal rotation of the femoral and/or tibial components in TKA has been associated with increased patellofemoral complications, anterior knee pain, premature polyethylene wear, arthrofibrosis, and early failure. [1ㅡㅇㅛ A6] Although early clinical outcome studies have shown promising results for kinematically aligned TKAs, the most common reason for revision was patellofemoral complications (1.2\%). [무] These included patellar instability, and anterior knee pain requiring lateral patellar facet excision. While these failures are likely multifactorial, it does bring up the concern that kinematically aligned TKAs may have a higher incidence of patellar problems because of the relatively higher incidence of internal femoral and tibial component rotation. Additionally, Boldt, et al. [87] observed a clear correlation between arthrofibrosis and placement of the femoral component internally rotated relative to the TEA.

\section{Does kinematic alignment work well for all knees} requiring TKA?

Does this concept work for all implant designs? Is it still safe to use this method in knees with severe angular deformity and ligamentous attenuation? It is known that the ACL serves as a secondary stabilizer of the lateral flexion gap. Flouroscopic studies of PCL-retaining TKAs have shown that femoral condylar lift-off predominately occurs laterally, believed secondary to loss of the stabilizing effect of the ACL. [88] Lateral femoral condylar lift-off increases medial condylar loads. If the tibial component is already positioned in varus, will this, in conjunction with loss of the ACL result in medial tibial overload and premature failure?

\section{Summary/Conclusions}

While extensive long-term data supporting reliable clinical outcomes and survivorship of mechanically aligned TKAs exists, there continues to be up to $20 \%$ of TKA patients who are not satisfied with their functional outcomes. While this reality is likely multifactorial in nature, and not solely due to knee alignment, it is also known that neutral mechanical alignment is not necessarily the anatomic normal. This has led some surgeons to advocate a paradigm shift in defining optimal component alignment. While short-term clinical and functional outcomes of kinematic alignment are promising, long-term clinical results and survivorship are still needed to make any lasting conclusions. Patients with large deformities in pre-operative alignment may benefit from a kinematic alignment with boundaries technique. Additionally, with increasing scrutiny of how health-care dollars are spent, it is unclear whether the adoption of expensive technology (i.e., computer navigation, patient-specific instrumentation, etc.) which may facilitate the precision required to attain ideal results with kinematic alignment, will be supported without long-term clinically superior results.

\section{References}

1. Schiraldi, M, Bonzanini, G, Chirillo, D, de Tullio, V: Mechanical and kinematic alignment in total knee arthroplasty. Ann Transl Med 2016;4:130.

2. Cherian, JJ, Kapadia, BH, Banerjee, S, Jauregui, JJ, Issa, K, Mont, MA: Mechanical, anatomical, and kinematic axis in TKA: Concepts and practical applications. Curr Rev Musculoskelet Med 2014;7:89-95.

3. Barrett, WP, Mason, JB, Moskal, JT, Dalury, DF, Oliashirazi, A, Fisher, DA: Comparison of radiographic alignment of imageless computer-assisted surgery vs conventional instrumentation in primary total knee arthroplasty. J Arthroplasty 2011;26:

4. D'Lima, DD, Hermida, JC, Chen, PC, Colwell, CW: Polyethylene wear and variations in knee kinematics. Clin Orthop Relat Res 2001;124-130.

5. Jeffery, RS, Morris, RW, Denham, RA: Coronal alignment after total knee replacement. J Bone Joint Surg Br 1991;73:709-14.

6. D'Lima, DD, Chen, PC, Colwell Jr., CW: Polyethylene Contact Stresses, Articular Congruity and Knee Alignment. Clin Orthop Relat Res 2001;392:232-238.

7. Oswald, MH, Jakob, RP, Schneider, E, Hoogewoud, HM: Radiological analysis of normal axial alignment of femur and tibia in view of total knee arthroplasty. $J$ Ar throplasty 1993;8:419-426.

8. Ensini, A, Catani, F, Leardini, A, Romagnoli, M, Giannini, S: Alignments and Clinical Results in Conventional and Navigated Total Knee Arthroplasty. Clin Orthop Relat Res 2006;457:156-162.

9. Berend, ME, Ritter, MA, Meding, JB, Faris, PM, Keating, EM, Redelman, R, Faris, GW, Davis, KE: The Chetranjan Ranawat Award: Tibial Component Failure Mechanisms in Total Knee Arthroplasty. Clin Orthop Relat Res 2004;428:26-34.

10. Sikorski, JM: Alignment in total knee replacement. J Bone Jt Surg Br 2008;90:1121-1127

11. Wasielewski, RC, Galante, JO, Leighty, RM, Natarajan, RN, Rosenberg, AG: Wear patterns on retrieved polyethylene tibial inserts and their relationship to technical considerations during total knee arthroplasty. Clin Orthop Relat Res 1994;31-43. at $\langle$ http://www.ncbi.nlm.nih.gov/pubmed/8119035>

12. Fang, DM, Ritter, MA, Davis, KE: Coronal Alignment in Total Knee Arthroplasty Just How Important is it? J Arthroplasty 2009;24:39-43.

13. Green, G V, Berend, KR, Berend, ME, Glisson, RR, Vail, TP: The effects of varus tibial alignment on proximal tibial surface strain in total knee arthroplasty: The posteromedial hot spot. J Arthroplasty 2002;17:1033-1039.

14. Ritter, MA, Davis, KE, Meding, JB, Pierson, JL, Berend, ME, Malinzak, RA, Bargren, J, Blaha, J, Freeman, M, Berend, M, et al.: The effect of alignment and BM on failure of total knee replacement. J Bone Joint Surg Am 2011;93:1588-96.

15. Ritter, MA, Faris, PM, Keating, M, Meding, JB: Postoperative Alignment of Total Knee Replacement Its Effect On Survival. Clin Orthop Relat Res 1994;299:153156.

16. Werner, FW, Ayers, DC, Maletsky, LP, Rullkoetter, PJ: The effect of valgus/ varus malalignment on load distribution in total knee replacements. J Biomech 2005;38:349-355.

17. Bourne, RB, Chesworth, BM, Davis, AM, Mahomed, NN, Charron, KDJ: Patient satisfaction after total knee arthroplasty: Who is satisfied and who is not? Clin Or thop Relat Res 2010;468:57-63.

18. Dossett, HG, Swartz, GJ, Estrada, N a., LeFevre, GW, Kwasman, BG: Kinematically Versus Mechanically Aligned Total Knee Arthroplasty. Orthopedics 2012;160-170.doi:10.3928/01477447-20120123-04.

19. Choong, PF, Dowsey, MM, Stoney, JD: Does Accurate Anatomical Alignment Result in Better Function and Quality of Life? Comparing Conventional and Computer-Assisted Total Knee Arthroplasty. J Arthroplasty 2009;24:560-569.

20. Huang, NFR, Dowsey, MM, Ee, E, Stoney, JD, Babazadeh, S, Choong, PF: Coronal Alignment Correlates With Outcome After Total Knee Arthroplasty: FiveYear Follow-Up of a Randomized Controlled Trial. J Arthroplasty 2012;27:17371741

21. Abdel, MP, Oussedik, S, Parratte, S, Lustig, S, Haddad, FS: Coronal alignment in total knee replacement. Bone Joint J 2014;96-B:857-862. 
22. Parratte, S, Pagnano, MW, Trousdale, RT, Berry, DJ: Replacements Fifteen-Year Survival of Modern, Cemented Total Knee Effect of Postoperative Mechanical Axis Alignment on the Effect of Postoperative Mechanical Axis Alignment on the Fifteen-Year Survival of Modern, Cemented Total Knee Replacements. J Bone Jt Surg Am 2010;92:2143-2149.

23. Bauwens, K, Matthes, G, Wich, M, Gebhard, F, Hanson, B, Ekkernkamp, A, Stengel, D: Navigated Total Knee Replacement. J Bone Jt Surgery, Am Vol 2007;89A:261-269.

24. Matziolis, G, Krocker, D, Weiss, U, Tohtz, S, Perka, C: A prospective, randomized study of computer-assisted and conventional total knee arthroplasty. Threedimensional evaluation of implant alignment and rotation. J Bone Joint Surg Am 2007;89:236-243.

25. Howell, SM, Howell, SJ, Kuznik, KT, Cohen, J, Hull, ML: Does a kinematically aligned total knee arthroplasty restore function without failure regardless of alignment category? Knee. Clin Orthop Relat Res 2013;471:1000-1007.

26. Howell, SM, Papadopoulos, S, Kuznik, KT, Hull, ML: Accurate alignment and high function after kinematically aligned TKA performed with generic instruments. Knee Surgery, Sport Traumatol Arthrosc 2013;21:2271-2280.

27. Howell, SM, Papadopoulos, S, Kuznik, K, Ghaly, LR, Hull, ML: Does varus alignment adversely affect implant survival and function six years after kinematically aligned total knee arthroplasty? Int Orthop 2015;39:2117-2124.

28. Hsu, RW, Himeno, S, Coventry, MB, Chao, EY: Normal axial alignment of the lower extremity and load-bearing distribution at the knee. Clin Orthop Relat Res 1990;215-227.doi:10.1097/00003086-199006000-00029.

29. Fahlman, L, Sangeorzan, E, Chheda, N, Lambright, D: Older adults without radiographic knee osteoarthritis: Knee alignment and knee range of motion. Clin Med Insights Arthritis Musculoskelet Disord 2014;7:

30. Victor, JMK, Bassens, D, Bellemans, J, Dhollander, AAM, Verdonk, PCM: SYMPOSIUM: 2013 KNEE SOCIETY PROCEEDINGS Constitutional Varus Does Not Affect Joint Line Orientation in the Coronal Plane. doi:10.1007/s11999-0132898-6.

31. Hungerford, DS, Krackow, KA: Total joint arthroplasty of the knee. Clin Orthop Relat Res 1985;23-33.at <http://www.ncbi.nlm.nih.gov/entrez/query.fcgi?cmd=R etrieve\&db=PubMed\&dopt=Citation\&list uids $=3967427>$.

32. Mason, JB, Fehring, TK, Estok, R, Banel, D, Fahrbach, K: Meta-Analysis of Alignment Outcomes in Computer-Assisted Total Knee Arthroplasty Surgery. J Arthroplasty 2007;22:1097-1106.

33. Insall, JN, Binazzi, R, Soudry, M, Mestriner, LA: Total knee arthroplasty. Clin Orthop Relat Res 1985;13-22.doi:10.1097/00003086-198501000-00008.

34. Bonner, TJ, Eardley, WGP, Patterson, P, Gregg, PJ: The effect of post-operative mechanical axis alignment on the survival of primary total knee replacements after a follow-up of 15 years. J Bone Jt Surg Br 2011;9393:1217-22.

35. Morgan, SS, Bonshahi, A, Pradhan, N, Gregory, A, Gambhir, A, Porter, ML: The influence of postoperative coronal alignment on revision surgery in total knee arthroplasty. Int Orthop 2008;32:639-642.

36. Vanlommel, L, Vanlommel, J, Claes, S, Bellemans, J: Slight undercorrection following total knee arthroplasty results in superior clinical outcomes in varus knees. Knee Surgery, Sport Traumatol Arthrosc 2013;21:2325-2330.

37. Magnussen, RA, Weppe, F, Demey, G, Servien, E, Lustig, S: Residual varus alignment does not compromise results of TKAs in patients with preoperative varus. Clin Orthop Relat Res 2011;469:3443-3450.

38. Hadi, M, Barlow, T, Ahmed, I, Dunbar, M, McCulloch, P, Griffin, D: Does malalignment affect revision rate in total knee replacements: a systematic review of the literature. Springerplus 2015;4:835.

39. Miller, EJ, Pagnano, MW, Kaufman, KR: Tibiofemoral alignment in posterior stabilized total knee arthroplasty: Static alignment does not predict dynamic tibial plateau loading. J Orthop Res 2014;32:1068-1074.

40. Specogna, A V, Birmingham, TB, Hunt, MA, Jones, IC, Jenkyn, TR, Fowler, PJ, Giffin, JR: Radiographic measures of knee alignment in patients with varus gonarthrosis: effect of weightbearing status and associations with dynamic joint load. Am J Sports Med 2007;35:65-70.

41. Deep, K, Eachempati, KK, Apsingi, S: The dynamic nature of alignment and variations in normal knees. Bone Jt $J$ 2015;97-B:498-502.

42. Delport, H, Labey, L, Innocenti, B, De Corte, R, Vander Sloten, J, Bellemans, $\mathrm{J}$ : Restoration of constitutional alignment in TKA leads to more physiological strains in the collateral ligaments. Knee Surgery, Sport Traumatol Arthrosc 2014;23:2159-2169.

43. Eckhoff, DG, Bach, JM, Spitzer, VM, Reinig, KD, Bagur, MM, Baldini, TH, Flannery, NMP: Three-dimensional mechanics, kinematics, and morphology of the knee viewed in virtual reality. J Bone Joint Surg Am 2005;87 Suppl 2:71-80.

44. Hollister, AM, Jatana, S, Singh, AK, Sullivan, WW, Lupichuk, AG: The axes of rotation of the knee. Clin Orthop Relat Res 1993;259-68.at <http://www.ncbi.nlm. nih.gov/pubmed/8472457>.
45. Howell, Stephen M., Hull, ML: Kinematic Alignment in Total Knee Arthroplasty. Insa Scott Surg Knee 2012;1255-1258.

46. Howell, SM, Roth, JD, Hull, ML: Kinematic Alignment in Total Knee Arthroplasty Definition , History , Principle , Surgical Technique , and Results of an Alignment Option for TKA. 2014;

47. Abdel, MP, Oussedik, S, Cross, MB: Clinical faceoff: Neutrally versus kinematically aligned TKA. Clin Orthop Relat Res 2015;473:27-31.

48. Bellemans, J: Neutral Mechanical Alignment: A Requirement for Successful TKA: Opposes. Orthopedics 2011;34:e507-e509.

49. Bellemans, J, Colyn, W, Vandenneucker, H, Victor, J: The chitranjan ranawat The Chitranjan Ranawat award: is neutral mechanical alignment normal for all patients? The concept of constitutional varus. Clin Orthop Relat Res 2012;470:4553.

50. Ecker, ML, Lotke, PA, Windsor, RE, Cella, JP: Long-term results after total condylar knee arthroplasty. Clin Orthop Relat Res 1987;March:151-158.

51. Feng, EL, Stulberg, SD, Wixson, RL: Progressive subluxation and polyethylene wear in total knee replacements with flat articular surfaces. Clin Orthop Relat Res 1994;60-71.at <http://www.ncbi.nlm.nih.gov/pubmed/8119038>.

52. Vandekerckhove, P-JTK, Matlovich, N, Teeter, MG, MacDonald, SJ, Howard, JL, Lanting, BA: The relationship between constitutional alignment and varus osteoarthritis of the knee. Knee Surgery, Sport Traumatol Arthrosc 2016;1-7. doi:10.1007/s00167-016-3994-4.

53. Hsu, HP, Garg, a, Walker, PS, Spector, M, Ewald, FC: Effect of knee component alignment on tibial load distribution with clinical correlation. Clin Orthop Relat Res 1989;135-144.doi:10.1097/00003086-198911000-00022.

54. Matsuda, S, Whiteside, LA, White, SE: The effect of varus tilt on contact stresses in total knee arthroplasty: a biomechanical study. Orthopedics 1999;22:303-307.

55. Collier, MB, Engh, CA, McAuley, JP, Engh, G a: Factors associated with the loss of thickness of polyethylene tibial bearings after knee arthroplasty. J Bone Joint Surg Am 2007;89:1306-14.

56. Pang, HN, Jamieson, P, Teeter, MG, McCalden, RW, Naudie, DDR, MacDonald, SJ: Retrieval analysis of posterior stabilized polyethylene tibial inserts and its clinical relevance. J Arthroplasty 2014;29:365-368.

57. Srivastava, A, Lee, GY, Steklov, N, Colwell, CW, Ezzet, KA, D'Lima, DD: Effect of tibial component varus on wear in total knee arthroplasty. Knee 2012;19:560563.

58. Bargren, JH, Blaha, JD, Freeman, M a: Alignment in total knee arthroplasty. Correlated biomechanical and clinical observations. Clin Orthop Relat Res 1983;178-183.

59. Howell, Stephen M., Hull, ML: Kinematic Alignment in Total Knee Arthroplasty: Definition, Surgical Technique, and Challenging Cases. Orthop Knowl Online 2012;10:

60. Hutt, JRB, LeBlanc, MA, Massé, V, Lavigne, M, Vendittoli, PA: Kinematic TKA using navigation: Surgical technique and initial results. Orthop Traumatol Surg Res 2016;102:99-104.

61. Shepherd, DE, Seedhom, BB: Thickness of human articular cartilage in joints of the lower limb. Ann Rheum Dis 1999;58:27-34.

62. Allen, MM, Pagnano, MW: Neutral mechanical alignment: Is it Necessary? Bone Joint $J$ 2016;98-B:81-83.

63. Bankes, MJK, Back, DL, Cannon, SR, Briggs, TWR: The effect of component malalignment on the clinical and radiological outcome of the Kinemax total knee replacement. Knee 2003;10:55-60.

64. Harvey, IA, Manning, MP, Sampath, SA, Johnson, R, Elloy, MA: Alignment of total knee arthroplasty: the relationship to radiolucency around the tibial component. Med Eng Phys 1995;17:182-7.

65. Dossett, HG, Estrada, NA, Swartz, GJ, LeFevre, GW, Kwasman, BG: A randomised controlled trial of kinematically and mechanically aligned total knee replacements: two-year clinical results. Bone Joint J 2014;96-B:907-13.

66. Nam, D, Nunley, RM, Barrack, RL: Patient dissatisfaction following total knee replacement: a growing concern? Bone Joint J 2014;96-B:96-100.

67. Howell, SM, Papadopoulos, S, Kuznik, K, Ghaly, LR, Hull, ML: Does varus alignment adversely affect implant survival and function six years after kinematically aligned total knee arthroplasty? Int Orthop 2015;39:2117-24.

68. Young, SW, Walker, ML, Bayan, A, Briant-Evans, T, Pavlou, P, Farrington, B: The Chitranjan S. Ranawat Award: No Difference in 2-year Functional Outcomes Using Kinematic versus Mechanical Alignment in TKA: A Randomized Controlled Clinical Trial. Clin Orthop Relat Res 2016;1-12.doi:10.1007/s11999-016-4844-x.

69. Meneghini, RM, Grant, TW, Ishmael, MK: Leaving residual varus alignment after total knee arthroplasty does not improve patient outcomes. J Arthroplasty 2017; doi:10.1016/j.arth.2017.02.064.

70. Courtney, PM, Lee, G-C: Early Outcomes of Kinematic Alignment in Primary Total Knee Arthroplasty: A Meta-Analysis of the Literature. J Arthroplasty 2017; doi:10.1016/j.arth.2017.02.041. 
71. Halder, A, Kutzner, I, Graichen, F, Heinlein, B: Influence of Limb Alignment on Mediolateral Loading in Total Knee Replacement. J Bone Jt Surg 2014;94:10231029.

72. Bonny, DP, Howell, SM, Hull, ML: Changes in the rotational axes of the tibiofemoral joint caused by resection of the anterior cruciate ligament. J Orthop Res 2016;doi:10.1002/jor.23308.

73. Simon, D, Mascarenhas, R, Saltzman, BM, Rollins, M, Bach, BR, MacDonald, P: The Relationship between Anterior Cruciate Ligament Injury and Osteoarthritis of the Knee. Adv Orthop 2015;2015:1-11.

74. Imhauser, C, Mauro, C, Choi, D, Rosenberg, E, Mathew, S, Nguyen, J, Ma, Y, Wickiewicz, T: Abnormal tibiofemoral contact stress and its association with altered kinematics after center-center anterior cruciate ligament reconstruction: an in vitro study. Am J Sports Med 2013;41:815-25.

75. Van de Velde, SK, Bingham, JT, Gill, TJ, Li, G: Analysis of tibiofemoral cartilage deformation in the posterior cruciate ligament-deficient knee. J Bone Joint Surg Am 2009;91:167-75.

76. Whiteside, LA, Arima, J: The anteroposterior axis for femoral rotational alignment in valgus total knee arthroplasty. Clin Orthop Relat Res 1995;168-72.at <http:// www.ncbi.nlm.nih.gov/pubmed/7497664>.

77. Berger, RA, Rubash, HE, Seel, MJ, Thompson, WH, Crossett, LS: Determining the rotational alignment of the femoral component in total knee arthroplasty using the epicondylar axis. Clin Orthop Relat Res 1993;40-7.at <http://www.ncbi.nlm. nih.gov/pubmed/8425366>.

78. Dennis, DA, Komistek, RD, Kim, RH, Sharma, A: Gap balancing versus measured resection technique for total knee arthroplasty. Clin Orthop Relat Res 2010;468:102-7.

79. Park, A, Duncan, ST, Nunley, RM, Keeney, JA, Barrack, RL, Nam, D: Relationship of the posterior femoral axis of the "kinematically aligned" total knee arthroplasty to the posterior condylar, transepicondylar, and anteroposterior femoral axes. Knee 2014;21:1120-1123.

80. Nedopil, AJ, Howell, SM, Hull, ML: Does Malrotation of the Tibial and Femoral Components Compromise Function in Kinematically Aligned Total Knee Arthroplasty? Orthop Clin North Am 2016;47:41-50.

81. Berger, RA, Crossett, LS, Jacobs, JJ, Rubash, HE: Malrotation Causing Patellofemoral Complications After Total Knee Arthroplasty. Clin Orthop Relat Res 1998;356:144-153.

82. Barrack, RL, Schrader, T, Bertot, AJ, Wolfe, MW, Myers, L: Component rotation and anterior knee pain after total knee arthroplasty. Clin Orthop Relat Res 2001;46-55.at <http://www.ncbi.nlm.nih.gov/pubmed/11716424>.

83. Anouchi, YS, Whiteside, LA, Kaiser, AD, Milliano, MT: The effects of axial rotational alignment of the femoral component on knee stability and patellar tracking in total knee arthroplasty demonstrated on autopsy specimens. Clin Orthop Relat Res 1993;170-7.at <http://www.ncbi.nlm.nih.gov/pubmed/8448937>.

84. Wasielewski, RC, Galante, JO, Leighty, RM, Natarajan, RN, Rosenberg, AG: Wear patterns on retrieved polyethylene tibial inserts and their relationship to technical considerations during total knee arthroplasty. Clin Orthop Relat Res 31-43.at $<$ http://www.ncbi.nlm.nih.gov/pubmed/8119035>.
85. Cameron, HU, Hunter, GA: Failure in total knee arthroplasty: mechanisms, revisions, and results. Clin Orthop Relat Res 1982;141-6.at <http://www.ncbi.nlm. nih.gov/pubmed/7127939>.

86. Fehring, TK: Rotational malalignment of the femoral component in total knee arthroplasty. Clin Orthop Relat Res 2000;72-9.at <http://www.ncbi.nlm.nih.gov/ pubmed/11064975>

87. Boldt, JG, Stiehl, JB, Hodler, J, Zanetti, M, Munzinger, U: Femoral component rotation and arthrofibrosis following mobile-bearing total knee arthroplasty. Int Orthop 2006;30:420-5.

88. Stiehl, JB, Komistek, RD, Dennis, DA, Paxson, RD, Hoff, WA: Fluoroscopic analysis of kinematics after posterior-cruciate-retaining knee arthroplasty. J Bone Joint Surg $\operatorname{Br} 1995 ; 77: 884-9$.

\section{SUBMISSION HISTORY}

Submitted October 23, 2018

Reviewed December 10, 2018

Accepted December 10, 2018

Published December 31, 2018

\section{AUTHOR AFFILIATIONS}

Thomas J Parisi, MD, JD'; Jason M Jennings, MD, DPT ${ }^{1,3}$; Douglas A Dennis, MD'1,2,3,4

1 Colorado Joint Replacement, Porter Adventist Hospital, Denver, CO

2 Adjunct Professor, Department of Biomedical Engineering, University of Tennessee, Knoxville, TN

3 Adjunct Professor of Bioengineering, Department of Mechanical and Materials Engineering, Denver University, Denver, CO

4 Assistant Clinical Professor, Department of Orthopaedics, University of Colorado School of Medicine, Denver, CO

Direct inquires to:

Douglas A Dennis, MD

Colorado Joint Replacement, 2535 S. Downing St., \#100, Denver, C0 80235 roseannjohnson@centura.org

\section{AUTHOR DISCLOSURES}

The authors declare that there are no disclosures regarding the publication of this paper.

\section{COPYRIGHT \& OPEN ACCESS}

(C) 2018 Parisi, Dennis, Jennings. All rights reserved. Authors retain copyright and grant the journal right of first publication with the work. Reconstructive Review is an open access publication and follows the Creative Commons Attribution-NonCommercial CC BY-NC. This license allows anyone to download works, build upon the material, and share them with others for non-commercial purposes as long as they credit the senior author, Reconstructive Review, and the Joint Implant Surgery \& Research Foundation (JISRF). An example credit would be: "Courtesy of (senior author's name), Reconstructive Review, JISRF, Chagrin Falls, Ohio". 